\title{
Polymerase Chain Reaction Detection of Pasteurella multocida Type B: 2 in Mice Infected with Contaminated River Water
}

\author{
${ }^{1,3}$ Faez Firdaus Jesse Abdullah, ${ }^{1,5}$ Mohammed Muqdad Khaleel, \\ ${ }^{1,6}$ Lawan Adamu, ${ }^{1,6}$ Abdinasir Yusuf Osman, ${ }^{1,3}$ Abdul Wahid Haron, \\ ${ }^{2}$ Mohd Zamri Saad and ${ }^{4}$ Abdul Rahman Omar

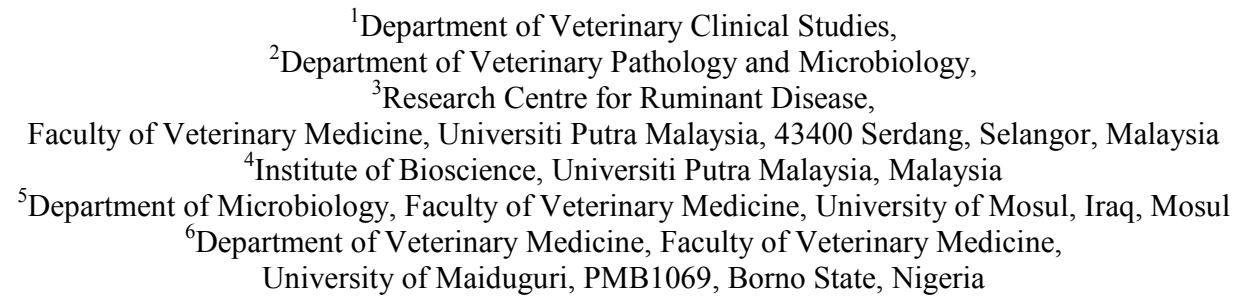

${ }^{1}$ Department of Veterinary Clinical Studies,

${ }^{2}$ Department of Veterinary Pathology and Microbiology,

${ }^{3}$ Research Centre for Ruminant Disease,

Faculty of Veterinary Medicine, Universiti Putra Malaysia, 43400 Serdang, Selangor, Malaysia

${ }^{4}$ Institute of Bioscience, Universiti Putra Malaysia, Malaysia

${ }^{5}$ Department of Microbiology, Faculty of Veterinary Medicine, University of Mosul, Iraq, Mosul

${ }^{6}$ Department of Veterinary Medicine, Faculty of Veterinary Medicine,

University of Maiduguri, PMB1069, Borno State, Nigeria

Received 2013-08-19, Revised 2013-09-11; Accepted 2013-09-17

\begin{abstract}
Hemorrhagic septicemia is an acute, deadly disease of cattle and buffaloes associated with colossal economic loss in the livestock industry in the Asian regions particularly Malaysia. Therefore, this study was conducted to investigate on the Polymerase chain reaction detection of Pasteurella multocida type B: 2 in mice inoculated through different routes with river water contaminated with infected mice carcasses. Sixty five mice were used for the study; five mice were placed in each tank containing river water for 24,48 and $72 \mathrm{~h}$. The groups comprise of five mice each made up of the control, intraperitoneal, oral and the aerosol routes. A dose of $1 \mathrm{~mL} 10^{9} \mathrm{CFU}$ of Pasteurella multocida type B: 2 obtained from the infected river water were inoculated into each group intraperitoneally and the aerosol route while, $0.4 \mathrm{~mL}$ of $10^{9} \mathrm{CFU}$ of Pasteurella multocida type B: 2 was inoculated orally into the group. The control group was inoculated with $1 \mathrm{~mL}$ buffer saline $\mathrm{pH}$ 7. The PCR results in the present study revealed the presence of $P$. multocida type B: 2 from the following organs brain, kidney, heart, spleen, lung and liver in the mice inoculated through intraperitoneal, oral and aerosol route. In the river water kept for $24 \mathrm{~h}$ P. multocida type B: 2 were detected in the organs through the intraperitoneal, oral and the aerosol routes. The river water kept for 48 and $72 \mathrm{~h}$ were positive for the isolation of $P$. multocida inoculated via the intraperitoneal and oral route, except the aerosol route where no significant $P$. multocida was detected in the organs using PCR. In conclusion, this model could be used to enhance the understanding of the progression of the disease and control of the natural disease through the various routes of the disease transmission. This study also postulated that the outbreak of HS among buffaloes and cattle could be due to the consumption of river water contaminated with infected HS carcasses.
\end{abstract}

Keywords: Detection, PCR, Pasteurella Multocida type B: 2, Different Routes, Contaminated River Water, Infected Mice Carcasses

Corresponding Author: Faez Firdaus Jesse Abdullah, Department of Veterinary Clinical Studies, Faculty of Veterinary Medicine, Universiti Putra Malaysia, 43400 Serdang, Selangor, Malaysia Tel: +60386093924 


\section{INTRODUCTION}

Hemorrhagic Septicemia (HS) is a lethal, deadly, septicemic disease of cattle and buffaloes caused by fastidious serotypes of Pasteurella multocida a Gram negative coccobacillus bacteria in the family Pasteurellaceae related with multiple acute diseases in livestock (Jesse et al., 2013a), P. multocida is an opportunistic pathogen (Ashraf et al., 2011) and serotype B: 2 is the most significant reason of the disease in Asia (Abubakar and Zamri-Saad, 2011) and in some parts of Africa (Jesse et al., 2013b) with momentous high morbidity and mortality leading to huge economic loss (OIE, 2008).

Nowadays, studies were carried out to investigate on the sources of infection with Pasteurella multocida in river water containing carcasses (Jesse et al., 2013c). Jesse et al. (2013c) detected Pasteurella multocida Type B: 2 in Mice following oral inoculation using polymerase chain reaction, $P$. multocida type B was successfully isolated from the heart, lung, liver, spleen, stomach, small intestine and large intestine of the mice from the treatment group which died during the 5 days of the experimental period. There was no proof of the presence of $P$. multocida type $\mathrm{B}$ in the organs isolated from the surviving mice (Jesse et al., 2013c).

In animals the progression of the disease has been regularly reported to occur following exposure of the vulnerable hosts to stressful states where infections generally occur by inhalation or ingestion (Shafarin et al., 2009). The clinical signs of HS can also occur through the ingestion of infected foodstuff (Shafarin et al., 2009; Ataei et al., 2009). The clinical symptom of this disease is often distinguished by rapid course, high fever, loud and stertorous breathing, profuse salivation, severe depression and followed by death generally within $24 \mathrm{~h}$ of infection (Boyce et al., 2010; Jesse et al., 2013). A recent study of experimental nature has substantiated the progression of typical clinical changes of HS following oral route of inoculation of Pasteurella multocida type B in buffaloes (Abubakar and Zamri-Saad, 2011). In disease diagnosis, identification of post mortem lesions had considerably aided in HS diagnosis where lesions such as typical swelling of the neck due to severe blood tinged, edema and other lesions in the respiratory tract have been generally detected in many cases with HS. However, there is still inadequate information about the pathogenicity and epidemiology of HS through the intraperitoneal, oral and aerosol routes with infected river water contaminated with mice carcasses kept for 24, 48 and $72 \mathrm{~h}$. Therefore, the present study aims to identify Pasteurella multocida type B: 2 using polymerase chain reaction after infection of mice through different routes with water contaminated with infected mice carcasses.

\section{MATERIALS AND METHODS}

Sixty five healthy male mice of eight to ten weeks old were used in this study. They were obtained from the Institute of Cancer Research (ICR) and kept at the Animal Resource Centre, Universiti Putra Malaysia. The animals were confirmed negative for $P$. multocida following culture of peripheral blood for bacterial isolation, housed in plastic cages and provided with water and pellet ad libitum. Five mice were kept in each plastic cage for the control and treatment groups. The mice were observed for 2 weeks prior to the experiment to make sure that they acclimatize to the environment and were healthy.

\subsection{Inoculums}

Throughout the experiments, the wild-type $P$. multocida B: 2 used in this study were obtained from stock culture. It was isolated from a previous outbreak of HS in the state of Kelantan, Malaysia. Identification of P. multocida was made using the Gram-staining method and biochemical characterization of oxidase, urea broth, Sulphur Indole Motility (SIM), Triple Sugar Iron (TSI) and citrate tests. The isolate was confirmed to be $P$. multocida type B: 2 by the Veterinary Research Institute (VRI) Ipoh, Perak. Pure stock culture that was stored on nutrient agar slants was sub-cultured onto $5 \%$ horse blood agar and incubated at $37^{\circ} \mathrm{C}$ for $18 \mathrm{~h}$. A single colony of $P$. multocida was selected and grown in brain Heart Infusion Broth (BHI), incubated in shaker incubator at $37^{\circ} \mathrm{C}$ for $24 \mathrm{~h}$ before the concentration was determined by McFarland Nephelometer Barium Sulfate Standards.

\subsection{Experimental Design in Mouse Model}

The river water was cultured to confirm that it was free from $P$. multocida type B: 2, the river water was obtained from Hulu Langat. Fifteen mice were initially inoculated with $1.0 \mathrm{~mL}$ of $10^{9}$ colony forming unit (cfu) of $P$. multocida type B: 2 intraperitoneally. After 7-8 h of post inoculation survived mice were euthanized by cervical dislocation and the carcasses were placed in a tank containing river water. Five mice were placed in each tank for 24, 48 and $72 \mathrm{~h}$ and $1 \mathrm{~mL}$ of the pure colony of $10^{9}$ of $P$. multocida type B: 2 were inoculated into five mice intraperitoneally and another five mice via the aerosol routes while $0.4 \mathrm{~mL}$ of $10^{9}$ of $P$. Multocida type B: 2 was inoculated into mice five orally, after $48 \mathrm{~h}$ the mice were euthanized by cervical dislocation. The fourth group consists of the control group which had five mice and was inoculated with $1.0 \mathrm{~mL}$ of sterile Phosphate Buffered Saline (PBS) pH7. Thereafter, the moribund mice and surviving mice after $48 \mathrm{~h}$ were euthanized and Post mortem was conducted and the 
following organs were sampled namely the brain, kidney, heart, spleen, lungs and liver. All the organs were cultured on the blood agar and incubated at $37^{\circ} \mathrm{C}$ for $24 \mathrm{~h}$. PCR was performed on the chosen samples according to the organs from all the mice.

\subsection{DNA Extraction}

Extraction in the present study was performed using boiling method. A few colonies from the cultures were transferred into an Eppendorf tube containing $50 \mu \mathrm{L}$ distilled water and the suspension was boiled at $100^{\circ} \mathrm{C}$ for $15 \mathrm{~min}$. After boiling, the suspension was immediately cooled on ice for $2 \mathrm{~min}$. Then, the suspension was centrifuged at 13,000 rpm for $5 \mathrm{~min}$. The upper phase was carefully transferred into another Eppendorf tube to be use as DNA template.

\subsection{PCR Condition}

The PCR was performed in a touchdown thermocycler in a total reaction volume $10 \mathrm{uL}$ of PCR buffer, $\mathrm{MgCl}_{2}, 250 \mathrm{uM}$ of deoxynucleotide triphosphate, $2 \mathrm{U}$ of Taq DNA polymerase and $1 \mathrm{uM}$ of each forward and reverse primer and $5 \mathrm{uL}$ of template DNA. Amplification was performed with 30 cycles following an initial denaturating step at $94^{\circ} \mathrm{C}$ for $5 \mathrm{~min}$. Each cycle involved denaturation at $94^{\circ} \mathrm{C}$ for $1 \mathrm{~min}$, annealing at $56^{\circ} \mathrm{C}$ for $1 \mathrm{~min}$, extension at $72^{\circ} \mathrm{C}$ for $2 \mathrm{~min}$ and final extension at $72^{\circ} \mathrm{C}$ for $5 \mathrm{~min}$.

\subsection{Primer Design}

The primer for the amplification of the P. multocida was referenced to (OIE, 2012). The forward primer used was KMT1SP6: 5'-GCT-GTA-AAC-GAA-CTC-GCCAC-3' while the reverse primer used was KMT1T7: 5'ATC-CGC-TAT-TTA-CCC-AGT-GG-3, for $P$. multocida in general. The base pair for P. multocida in general was 460. The forward primer used was KTSP61: 5'-ATC-CGC-TAA-CAC-ACT-CTC-3' while the reverse primer used was KTT72: 5'-AGG-CTC-GTTTGG-ATT-ATG-AAG-3' for P. multocida type B: 2 . The base pair for $P$. multocida in general was 620. PCR amplification with the primer pair design during the sequencing of clone $6 \mathrm{~b}$ (KMT1SP6-KMT1T7) specifically produced a product approximately 460bp from HS- causing $P$. multocida. PCR amplification with the primer pair design during the sequencing of clone $6 \mathrm{~b}$ (KTSP61-KTT72) specifically produced a product approximately $620 \mathrm{bp}$ from HS- causing P. multocida type B. These primers were unable to amplify DNA from other P. Multocida species and other numbers of pasteurellacea family or unrelated bacteria.

\subsection{Agarose Gel Preparation}

About $1.5 \%$ agarose gel was prepared; $1.5 \mathrm{~g}$ agarose gel powder was poured into $100 \mathrm{~mL}$ bijour bottle, then top up with $1 \%$ TAE to $100 \mathrm{~mL}$. The mixture was heated in microwave oven for about 3-5 min until all the precipitate melted, liquid form gel was then leave to cool down to $60^{\circ} \mathrm{C}$. After that it was poured into suitable size cast. Wait for the gel to solidify for about $30 \mathrm{~min}$. After the gel was solidified and turns to cloudy white color the gel was then ready for PCR loading and electrophoresis.

\subsection{Electrophoresis}

Agarose gel was placed into the gel holder tank and submerged with $1 \%$ TAE buffer and placing the holding wells near the negative terminal to allow the band to run towards the positive terminal. Make sure the positive and negative terminals are placed properly. One hundred bp marker (Promega) was used. Five uL of PCR product was loaded into the well carefully without breaking it with the pipette. One $\mathrm{uL}$ of loading dye was mixed with $2 \mathrm{uL}$ ladders by using pipette and loaded into the first well. The PCR were run in $1.5 \%$ agarose gel for $40 \mathrm{~min}$ at $90 \mathrm{~V}$. Than the gel was stained with ethidium bromide $0.5 \mathrm{ug}$ $\mathrm{mL}^{-1}$ solutions and stirred for $20 \mathrm{~min}$, then the gel was dip into distilled water. Lastly, the gel was placed under UV gel imaging capturing machine and the results was recorded. Thereafter, the moribund mice and surviving mice after $48 \mathrm{~h}$ were euthanized and Post mortem was conducted and the following organs were sampled namely the brain, kidney, heart, spleen, lungs and liver. All the organs were cultured on the blood agar and incubated at $37^{\circ} \mathrm{C}$ for $24 \mathrm{~h}$. PCR was performed on the chosen samples according to the organs from all the mice.

\section{RESULTS}

The PCR results in the present study revealed the isolation of $P$. multocida from the following organs brain, kidney, heart, spleen, lung and liver in the mice inoculated through intraperitoneally, orally and aerosol route. In the river water kept for $24 \mathrm{~h}$ there were positive identification of $P$. multocida inoculated through the intraperitoneal, orally and the aerosol routes (Table 1 and Fig. 1). The river water kept for 48 and $72 \mathrm{~h}$ were positive for the isolation of $P$. multocida inoculated via the intraperitoneal and oral route, except the aerosol route where no $P$. multocida was identified in the organs using PCR (Table 2 and Fig. 2). 


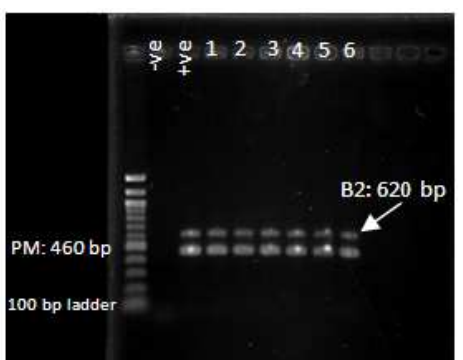

(A)

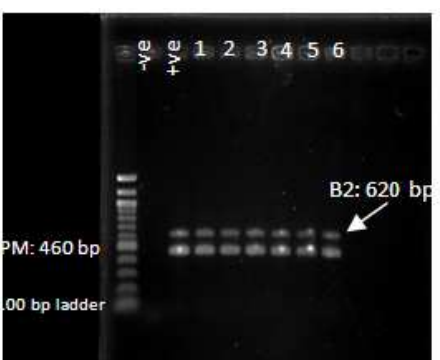

(B)

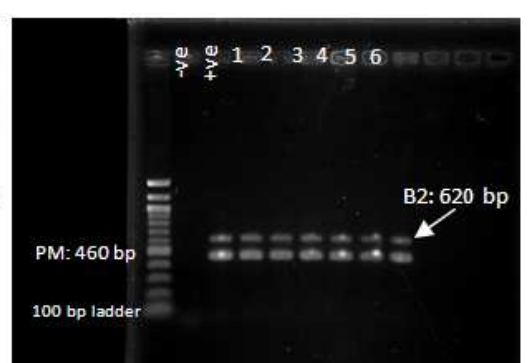

(C)

Fig. 1. PCR identification of $P$. multocida type B: 2 in organs inoculated through different routes with river water contaminated with infected mice carcasses kept for $24 \mathrm{~h}$. $\mathrm{A}=$ Intraperitoneal route; $\mathrm{B}=$ Oral route; $\mathrm{C}=$ Aerosol route. $1=\mathrm{Brain} ; 2=$ Kidney; 3 = Heart; 4 = Spleen; 5 = Lung; $6=$ Liver

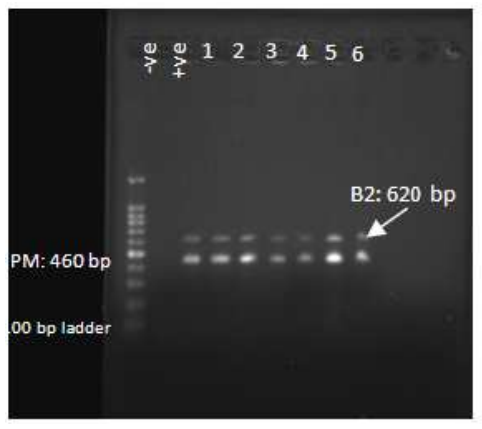

(A)

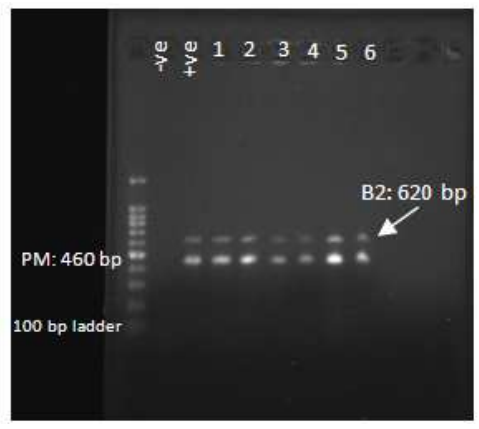

(B)

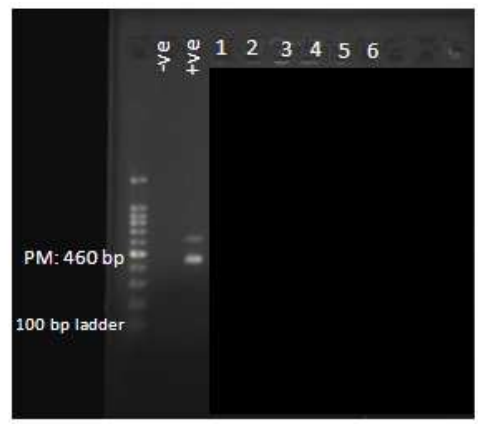

(C)

Fig. 2. PCR identification of $P$. multocida type $B: 2$ in organs inoculated through different routes with river water contaminated with infected mice carcasses kept for $48 \mathrm{~h}$. $\mathrm{A}=$ Intraperitoneal route; $\mathrm{B}=$ Oral route; $\mathrm{C}=$ Aerosol route (negative); $1=$ Brain; 2 = Kidney; 3 = Heart; 4 = Spleen; 5 = Lung; 6 = Liver

Table 1. Status of organs kept for $24 \mathrm{~h}$ in river water infected with P. multocida

\begin{tabular}{lll}
\hline & Status & \\
\cline { 2 - 3 } Organs & Positive & Negative \\
\hline Brain & IP,OR,AE & NA \\
Kidney & IP,OR,AE & NA \\
Heart & IP,OR,AE & NA \\
Spleen & IP,OR,AE & NA \\
Lung & IP,OR,AE & NA \\
Liver & IP,OR,AE & NA \\
\hline IP $=$ Intraperitoneally; OR = Orally; AE = Aerosol; NA $=$ Not
\end{tabular}

Table 2. Status of organs kept for $48 \mathrm{~h}$ in river water infected with P. multocida

\begin{tabular}{lll}
\hline & Status & \\
Organs & Positive & Negative \\
\hline Brain & IP,OR & AE \\
Kidney & IP,OR & AE \\
Heart & IP,OR & AE \\
Spleen & IP,OR & AE \\
Lung & IP,OR & AE \\
Liver & IP,OR & AE \\
\hline
\end{tabular}

$\mathrm{IP}=$ Intraperitoneally; OR = Orally; AE = Aerosol

\section{DISCUSSION}

Following intraperitoneal, oral and aerosol routes of P. multocida type B: 2 inoculations with infected river water kept for $24 \mathrm{~h}$ established hemorrhagic septicemia in the mouse model in the current study. Similar observations have been reported in cattle, buffaloes and goats following experimental infection with $P$. multocida B: 2 (Jesse et al., 2013c; Zamri-Saad and Shafarin, 2007), they suggested that the efficacy of certain route of infection can be established by observing the number of animals that died per-acutely following experimental infection with $P$. multocida type B: 2 . In the study they conducted, $60 \%$ of the goats died per-acutely following subcutaneous route of infection. The subcutaneous route of infection was regarded as the best technique for experimental induction of the disease in goats. In the present study 5 mice each were inoculation with the infected river water kept for 24, 48 and $72 \mathrm{~h}$ orally, intraperitoneally and by the aerosol route. Subsequently, the doses of $0.4 \mathrm{~mL}$ of $10^{9} \mathrm{cfu}$ inoculated orally and 1 $\mathrm{mL}$ of $10^{9} \mathrm{cfu}$ inoculated intraperitoneally and by the aerosol routes were able to produce the disease in the 
mouse model which lead to the per-acute death of the animals within 24,48 and $72 \mathrm{~h}$ of post inoculation. The animals in the intraperitoneal group died faster compared to oral and the aerosol groups.

The results obtained from the current study is similar to the study carried out by Jesse et al. (2013c) where they detected $P$. multocida Type B: 2 in mice following oral inoculation using polymerase chain reaction, $P$. multocida type B was successfully isolated from the heart, lung, liver, spleen, stomach, small intestine and large intestine of the mice from the treatment group which died during the 5 days of the experimental period. However, there was no proof of the presence of $P$. multocida type B in the organs isolated from the surviving mice in a study conducted by Jesse et al. (2013c).

According to the PCR result derived from the intraperitoneal, oral and the aerosol routes within 24, 48 and $72 \mathrm{~h}$ of infection with infected river water with $P$. multocida type B: 2 were able to induced infections in the following organs namely brain, kidney, heart, spleen, lung and liver with the exception of the aerosol routes at 48 and $72 \mathrm{~h}$ where no infections were detected using PCR in all the organs. The existence of $P$. multocida type $\mathrm{B}: 2$ in the organs using PCR detection technique were similar with the findings of Zamri-Saad and Shafarin (2007), through the subcutaneous and the intra-tracheal routes in goats. The isolation of $P$. multocida type $\mathrm{B}: 2$ from the heart in the current study in the river water kept for $24 \mathrm{~h}$ was similar to the study carried out by Ashraf et al. (2011); Khin et al. (2010); Zamri-Saad and Shafarin (2007) and Shafarin et al. (2009) via intra-nasal, intra-tracheal, subcutaneous and the intraperitoneal routes of infections.

\section{CONCLUSION}

In conclusion, identification and isolation of $P$. multocida type B: 2 from infected river water kept for $24 \mathrm{~h}$ using PCR revealed positive results in organs of the mice inoculated intraperitoneally, orally and by the aerosol routes. Furthermore, no $P$. multocida type B: 2 were detected in the organs of the mice inoculated by the aerosol route with the river water kept for 48 and $72 \mathrm{~h}$ using PCR. Therefore, the intraperitoneal route is the most effective route of HS induction and it could also portray an effective and efficient route for effective and heightened immunomodulatory establishment. Additionally, this model could be used to enhance the understanding of the progression of the disease and control of the natural disease through the various routes of the disease transmission. This study also postulated that the outbreak of HS among buffaloes and cattle could be due to the consumption of river water contaminated with infected HS carcasses.

\section{ACKNOWLEDGEMENT}

We thank the staff of the Department of Veterinary Clinical Studies, Universiti Putra Malaysia and Research Centre for Ruminant Disease, in particular Yap Keng Chee, Mohd Jefri Norsidin and Mohd Fahmi Mashuri for their assistance. The project was funded by Ministry of Higher Education Malaysia.

\section{REFERENCES}

Abubakar, M.S. and M. Zamri-Saad, 2011. Clinicopathological changes in buffalo calves following oral exposure to Pasteurella multocida B: 2. Basic Applied Pathol., 4: 130-135. DOI: 10.1111/j.17559294.2011.01113.x

Ashraf, A.H., S. Tariq, S.S. Nadeem and I. Manzoor, 2011. Characterization of Pasteurella multocida strains isolated from cattle and buffaloes in Karachi, Pakistan. Afr. J. Micrabiol. Res., 5: 4673-4677. DOI: 10.5897/AJMR11.068

Ataei, S.R., J.C. Burchmore, A. Hodgson, R. Finucane and J.G. Coate, 2009. ldentification of immunogenic proteins associated with protection against haemorrhagic septicaemia after vaccination of calves with a live-attenuated araA derivative of Pasteurella multocida B: 2. Res. Vet. Sei., 87: $207-$ 210. DOI: 10.1016/j.rvsc.2009.01.007

Boyce, J.D., M. Harper, I.W. Wilkieand and B. Adler, 2010. Pasteurella. In: Pathogenesis of Bacterial Infections in Animals, Gyles, C.L., J.F. Prescott, G. Songer and C.O. Thoen (Eds.), Wiley, Ames, ISBN-10: 0470958219, pp: 325-346.

Jesse, F.F.A., L. Adamu, Y.O. Abdinasir, Z. Zakaria and R. Abdullah et al., 2013a. Clinico-pathological responses of calves associated with infection of Pasteurella multocida type B and the bacterial Lipopolysaccharide and outer membrane protein immunogens. Int. J. Anim. Vet. Adv., 5: 190-198.

Jesse, F.F.A., L. Adamu, Y.O. Abdinasir, Z. Zakaria and R. Abdullah et al., 2013b. Acute phase protein profile in calves following infection with whole cell, lipopolysaccharide and outer membrane protein extracted from Pasteurella multocida type B: 2. Asian J. Anim. Vet. Adv., 8: 655-662. DOI: 10.3923/ajava.2013.655.662

Jesse, F.F.A., Y.O. Abdinasir, L. Adamu, M.Y. Syamil and A.R. Omar et al., 2013c. Polymerase Chain reaction detection of pasteurella multocida type B: 2 in Mice Following Oral Inoculation. Asian J. Anim. Vet. Adv., 8: 493-501. DOI: 10.3923/ajava.2013.493.501 
Khin, M.N., M. Zamri-Saad and M.M. Noordin, 2010. Pathological changes in the Jung of calves following intratracheal exposure to Pasteurella multocida B: 2. Pertanika J. Trap. Agric. Sei., 33: 113-117. DOI: 10.1016/j.jcpa.2008.10.005

OIE, 2008. Haemorrhagic septicemia. Terrestial Manual, pp: 739-751.

OIE, 2012. Haemorrhagic septicemia. Terrestial Manual, pp: 1-13.
Shafarin, M.S., M. Zamri-Saad, B.S. Khairani and A.A. Saharee, 2009. Pathological changes in the respiratory tract of goats infected by Pasteurella multocida B:2. J. Camp. Path, 140: 194-197. DOI: 10.1016/j.jcpa.2008.10.005

Zamri-Saad, M. and M.S. Shafarin, 2007. Response of goats to the different routes of infection by Pasteurella multocida B: 2. J. Anim. Vet. Adv., 6: 340-343. 